\title{
Assessment of aggression in psychiatric admissions: semistructured interview and case note survey
}

\author{
Jonathan Sanders, Steven Milne, Phillip Brown, Angus J Bell
}

Editorial by Shaw

St Luke's Hospital, Middlesbrough

TS4 $3 \mathrm{AF}$

Jonathan Sanders specialist registrar

Steven Milne

consultant forensic psychiatrist

Phillip Brown consultant forensic psychiatrist

Angus J Bell consultant psychiatrist

Correspondence to: S Milne

BMJ 2000;320:1112
Most mentally ill people are not violent, and most violence is carried out by mentally well people. ${ }^{1}$ Nevertheless psychiatric illness is associated in the public mind with violence. ${ }^{23}$ Psychiatric assessment routinely examines suicidality, but how commonly clinicians ask patients about other forms of aggressive ideation is unclear.

We aimed to measure the prevalence of aggressive ideation among patients admitted to psychiatric hospitals, and how frequently examining psychiatrists asked about such thoughts.

\section{Participants, methods, and results}

Ethical approval was granted by South Tees Medical Ethics Committee. Over three months, one author (JS) spent one day a week interviewing all available patients admitted to the general psychiatric wards at St Luke's Hospital, Middlesbrough, in the preceding week. We sought individual consent and advised patients that information might be shared with clinical staff. We devised a semistructured interview to ask patients about self harm, destruction of property, and interpersonal violence. We noted the case note diagnoses from ICD-10 (international classification of diseases, 10th revision). We examined case notes for evidence that the admitting teams had asked about aggressive ideation. Statistical analyses used $\chi^{2}$ and Mann-Whitney U tests.

Of the 199 people admitted, 114 (57\%) were available for interview. Those available did not differ from others admitted in terms of age, sex, diagnosis, or legal status. The 16 of the 114 who did not consent to interview did not differ significantly from those consenting in terms of age, sex, diagnosis, or legal status.

The table summarises reported aggressive ideation, along with case notes giving evidence of inquiry about such thoughts.

Women reported more depressive thoughts than men $\left(\chi^{2}=6.18, \mathrm{df}=1, \mathrm{P}=0.01\right)$. Patients with a diagnostic category of psychosis according to ICD-10 reported fewer depressive thoughts than other categories $\left(\chi^{2}=8.59, \mathrm{df}=2, \mathrm{P}=0.01\right)$.

Patients with affective and psychotic disorders according to ICD-10 were less likely to report a history of property damage $\left(\chi^{2}=7.58, \mathrm{df}=2, \mathrm{P}=0.02\right)$.

Altogether 24 people had had violent thoughts about specific individuals; 17 (17.3\%) reported convictions for violence; nine admitted owning weapons; and five said that they regularly carried weapons. Violent thoughts, thoughts against specific individuals, ownership of weapons, and previous violence were associated with younger patients (Mann-Whitney $\mathrm{U}$ test, $\mathrm{P}=0.03$, $\mathrm{P}<0.05, \mathrm{P}=0.04, \mathrm{P}=0.005$, respectively). Detained patients reported more recent interpersonal violence thoughts than non-detained ones $\left(\chi^{2}=6.45\right.$, $\mathrm{df}=2$, $\mathrm{P}=0.04)$. Those who agreed to participate in the study were as likely as those refusing to participate to be
Number (\%) of self reported aggressive ideation and evidence of inquiry by admitting team in case notes $(n=114)$

\begin{tabular}{lccc} 
& \multicolumn{3}{c}{ Aggressive ideation } \\
\cline { 2 - 4 } & Self harm & $\begin{array}{c}\text { Damage to } \\
\text { property }\end{array}$ & $\begin{array}{c}\text { Interpersonal } \\
\text { violence }\end{array}$ \\
\hline Interview (n=98) & & \\
\hline In preceding week: & & \\
\hline Thoughts & $46(46.9)$ & $28(28.6)$ & $29(29.6)$ \\
\hline Behaviour & $17(17.3)$ & $13(13.3)$ & $14(14.3)$ \\
\hline Ongoing thoughts & $12(12.2)$ & $9(9.2)$ & $6(6.1)$ \\
\hline Inquiry by clinical team & $107(93.9)$ & $3(2.6)$ & $15(13.2)$ \\
\hline Case notes (n=114) & & & \\
\hline History of behaviour & $57(58.2)$ & $37(37.8)$ & $52(53.1)$ \\
\hline
\end{tabular}

asked about their suicidal ideation $\left(\chi^{2}=1.31, \mathrm{df}=1\right.$, $\mathrm{P}=0.25)$; violence to property $\left(\chi^{2}=0.50, \mathrm{df}=1\right.$, $\mathrm{P}=0.48)$; or violence to persons $\left(\chi^{2}=2.82, \mathrm{df}=1\right.$, $\mathrm{P}=0.09)$. Men were asked more often than women about suicidal ideation $\left(\chi^{2}=5.56, \mathrm{df}=1, \mathrm{P}=0.02\right)$. Informal patients were more likely to be asked about suicidal ideation $\left(\chi^{2}=20.62, \mathrm{df}=2, \mathrm{P}<0.0001\right)$ and about interpersonal violence $\left(\chi^{2}=6.75, \mathrm{df}=2, \mathrm{P}=0.03\right)$ than patients who had been sectioned.

\section{Comment}

Thoughts of violence to self among patients admitted to psychiatric hospital were common and were asked about by the teams who admitted them. Other violent thoughts were also commonly encountered, yet clinicians asked about them infrequently. Almost a quarter of patients reported thoughts of violence directed at specific individuals. Nearly 1 in 10 admitted to owning weapons and one in 20 to carrying them. Owning and carrying weapons are recognised risks for violence. ${ }^{4}$ We have a responsibility to inquire systematically about the full range of aggressive ideation.

We thank Dr Alan Kerr for his comments on an early draft of the paper.

JS discussed and helped formulate the original idea, performed the literature search, collected all of the data, and also participated in writing. SM initiated and coordinated the original idea, participated in the design of the protocol, analysed the data, participated in writing the paper, and acts as guarantor. $\mathrm{PB}$ and $\mathrm{AJB}$ participated in the study design and the writing.

Funding: None.

Competing interests: None declared.

1 Reed J. Risk assessment and clinical risk management: the lessons from recent inquiries. Br J Psychiatry 1997;170(suppl 32):4-7.

2 Byrne P. Fall and rise of the "psycho-killer." Psychiatr Bull 1998;22:174-6.

3 Appleby L, Wessely S. The influence of the Hungerford massacre on the public opinion of mental illness. Med Sci Law 1988;28:291-5.

4 Ferris LE, Sandercock J, Hoffman B, Silverman M, Barkun H, Carlisle J, et al. Risk assessments for acute violence to third parties: a review of the literature. Can J Psychiatry 1997;42:1051-60.

(Accepted 29 January 2000) 